\title{
IMPROVEMENT OF LOW-VELOCITY IMPACT AND COMPRESSION-AFTER-IMPACT PERFORMANCE BY Z-FIBRE PINNING
}

\author{
X Zhang ${ }^{1^{*}}$, L Hounslow ${ }^{2}$, M Grassi ${ }^{3}$ \\ ${ }^{1}$ Aerospace Engineering Group, School of Engineering, \\ Cranfield University, Bedford, MK43 OAL, United Kingdom \\ ${ }^{2}$ Aerospace and Telecommunications Engineering Support Squadron, \\ Canadian Forces Base Trenton, Astra, Ontario, K0K 3W0, Canada \\ ${ }^{3}$ Composite Design and Manufacturing, Applied Materials, QinetiQ, \\ Farnborough, Hants. GU14 OLX, United Kingdom
}

\begin{abstract}
Z-fibre pinning is a new method of through-thickness reinforcement of laminated composites. This paper presents an experimental test and theoretical analysis on how and why these pins can improve the resistance to impact loading and post-impact compression. Specimens were made of carbon/epoxy T300/914C with nominal thicknesses of 2, 4, and $6 \mathrm{~mm}$. For the specimens tested in this study, z-pinning reduced impact damage area by $19-64 \%$ depending on the specimen thickness and impact energy. Experimental results obtained also indicate that $z$-pins can significantly increase the compression-afterimpact (CAI) strength by about $45 \%$. In this paper all of these observations are discussed in the context of theoretical and numerical models that have been developed previously to predict the critical impact force and z-pinning performance in terms of the laminate in-plane stiffness and mode I delamination fracture toughness with the z-fibre bridging effect.
\end{abstract}

KEYWORDS: Z-fibre, Z-pinning, impact damage, compression-after-impact (CAI), delamination, damage tolerance.

\section{INTRODUCTION}

Advanced carbon fibre reinforced plastics (CFRPs) have been widely used in the aerospace industry, and the application is going to increase rapidly in order to reduce the payload and hence to enhance the performance. However, the poor properties in the through-thickness direction make CFRPs particularly susceptible to low velocity impact damage. This damage can be caused by dropping tools, runway debris, or flying through hailstorms. This impact damage is of particular concern because it is often barely visible from the impacted side. There may only be a small indent on the impacted face while significant delamination exists internally and significant matrix cracking exists on the back face. Due to the nature of aircraft structures, the back face of the laminate is often in an area that is not easily accessible and thus the damage often goes undetected. This damage can seriously degrade the laminate's compressive strength. Because this kind of damage often goes undetected, designers must allow for this so-called barely visible impact damage (BVID). A design

\footnotetext{
${ }^{*}$ Corresponding author. Tel.: +44 1234 754621; Fax: +44 1234 758203. E-mail address: xiang.zhang@cranfield.ac.uk
} 
strain-to-failure limit of $0.3-0.4 \%$ is currently used for aircraft compression panels while the undamaged material should be capable of strain limits of $1 \%$ or higher [1-5].

Two methods can be adopted to allow designers to use higher strain-to-failure limits and thus decrease the weight of the component. The first method is to improve the detection capability of the BVID. Adding more access panels to allow visual inspection of the back face is often unpractical due to the number of access panels required and their location on leading edges and flight controls. Detecting the damage using non-destructive testing such as c-scan or x-ray is also unpractical due to the amount of time required for the testing and the removal of components from the aircraft. The second method is to improve the throughthickness properties of the laminate in an attempt to reduce the accidental damage or to make the parts more damage tolerant under the service loads and operational conditions. Stitching or inserting short rods or pins in the thickness direction (often referred to as the z-direction) have been shown to greatly improve the fracture toughness in modes I and II [6]. The recently developed Z-Fibre technique involves inserting metal pins or cured carbon fibre pins into the laminate through the laminate thickness, and it offers significant improvement in impact resistance, compression-after-impact (CAI) strength, and the ultimate strength of stiffener pull-off [6-10].

Although the number of studies on impact performance of z-pinned laminates is very limited, it has been repeatedly reported in the literature that z-fibre pinning results in severely restricted size and growth of impact damage, and substantially improved CAI strength. Dickinson et al comprehensively reviewed the through-thickness reinforcement technique during its early development period of 1989-99, and summarised that by zpinning the CAI strength was improved by up to 50\%, impact damage area was reduced by up to 55\%, and the critical strain energy release rates were increased by a factor of 18 [6]. In [10] the structural response to impact damage of a generic skin-stringer panel was investigated. The stringer panel was pinned with $15 \mathrm{~mm}$ wide bands of $\mathrm{z}$-fibres to the skin adjacent to the stringers. Low velocity impacts $(35 \mathrm{~J})$ were then introduced in the bay and over the stringer foot, and the panels were subsequently subjected to compression test until failure. Although the impact sites were not located at the z-pinned regions, delamination cracking was restricted in the pinned regions achieving significant improvements in impact resistance and post-impact compressive strength. For the bay impacts, the presence of the zpins appeared to have reduced the impact damage area by $40 \%$ and a $32 \%$ increase in CAI strength was observed. Regarding the different damage stages, work in [9] has shown that zpinning does not improve the resistance to the onset of delamination damage. In fact, the critical impact force associated with the initiation of delamination in a quasi-isotropic sample is lowered by the presence of the z-pins. However, z-pinning does reduce the scale of delamination growth. For a given impact energy z-pinned samples exhibit considerably smaller overall delamination area than their unpinned counterparts [9].

In this paper, we aim at investigating the effect of z-pinning on the initiation and propagation stages of delamination damage due to low velocity impact, and the subsequent compressive strength. The study was carried out over a range of specimen thicknesses and impact energies in order to determine the effectiveness of z-pinning and its dependency on sample thickness and impact energy. The impact tests were analysed in terms of the critical impact force and damage area. The CAI tests were discussed in the context of an FE model 
that simulates the z-pin bridging effects and the increased apparent fracture toughness of zpinned laminates.

\section{EXPERIMENTAL}

All specimens were manufactured from one batch of carbon/epoxy T300/914C unidirectional pre-preg of nominal thickness $0.125 \mathrm{~mm}$ supplied by Hexcel Composites. The basic material properties for the pre-preg were obtained from the manufacturer and are given in Table 1. All samples were $100 \mathrm{~mm}$ by $150 \mathrm{~mm}$ with nominal thicknesses of 2, 4, and 6 $\mathrm{mm}$. To manufacture these specimens, four larger panels, each $660 \mathrm{~mm}$ by $360 \mathrm{~mm}$, were fabricated. All panels had a quasi-isotropic lay-up sequence: $[0 /+45 / 90 /-45]_{2 S}$ for the $2 \mathrm{~mm}$ thick panel, $[-45 / 0 /+45 / 90]_{4 \mathrm{~S}}$ for the $4 \mathrm{~mm}$ panel, and $[0 /+45 / 90 /-45]_{6 \mathrm{~S}}$ for the two $6 \mathrm{~mm}$ thick panels. Half of the specimens of each thickness were pinned at the plate centre with a pinned area of 50 x $50 \mathrm{~mm}$ as illustrated in Fig. 1a.

The Z-fibres were made of T300 carbon fibres embedded in bismaleimide (BMI) resin. These pins were held in a foam perform to support them as they were inserted into the uncured panel using a UAZ-2000 ${ }^{\mathrm{TM}}$ ultrasonic insertion gantry which allowed the pins to be inserted with a vertically applied uniform force. In this study the pin diameter was $0.28 \mathrm{~mm}$ and the areal density of the pins was $2 \%$ resulting in a distance of $1.75 \mathrm{~mm}$ between adjacent pins. After the pins were sheared, the panels were cured. Following the post-cure, the panels were each cut into twelve individual $150 \mathrm{~mm}$ by $100 \mathrm{~mm}$ specimens.

The support fixture for the impact tests is shown in Fig. 1a. Each specimen was held in place by four clamps with rubber tips. There is a 125 x $75 \mathrm{~mm}$ cutout below the specimen. The four clamps can be adjusted in height to accommodate the different specimen thicknesses so that all specimens of that thickness were clamped with approximately the same force. The fixture provides a support that is very close to the clamped boundary condition along the $125 \mathrm{~mm}$ by $75 \mathrm{~mm}$ window edges, but bending is not fully constrained. The impact tests were performed on a Rosand Instrumented Falling Weight Impact Tester (Type 5). In all impact tests, the impact energy was set. A hemispherical steel striker was used. The striker diameter was $20 \mathrm{~mm}$ and the striker mass was $0.177 \mathrm{~kg}$. The total drop mass and height were changed to accommodate the wide variety of impact energies. The drop mass, drop height, impact energy, and the number of samples used for each test case are listed in Table 2. The force and time histories were recorded by a high-speed transient recorder. An optical triggering source was used to initiate recording. About 4000 data points were recorded over a sweep time of $10 \mathrm{~ms}$ with $2 \%$ of the data points recorded prior to the impact event.

After impact tests, all the $4 \mathrm{~mm}$ thick specimens and selected $6 \mathrm{~mm}$ specimens were subjected to compression tests to determine their compression-after-impact (CAI) characteristics and strength. The support rig is illustrated in Fig. 1b. The specimens were fully clamped at both loaded edges and simply supported on the sides to prevent global buckling during the compression tests. This ensured that the specimens failed by delamination propagation at the impact position. The window size of the CAI support is $85.5 \mathrm{~mm}$ by $134 \mathrm{~mm}$. All tests were performed under displacement control at a rate of 1.5 
$\mathrm{mm} / \mathrm{min}$. Data sets of the load and displacement were obtained at a rate of 10 data sets per second. From these data sets, the initial displacement of the machine when load is first applied, the force at failure of the specimen and the displacement of the machine at failure of the specimen were obtained for all specimens. Details of the impact and compression tests can be found in [11].

\section{RESULTS \& ANALYSIS}

\subsection{Damage area}

In this study, the damage area was measured by ultrasonic C-scan imaging. Therefore, the term delamination area means the projected delaminated area and not calculated cumulative areas of superimposed delamination layers. The general shape of delamination area was roughly circular. Fig. 2 shows typical C-scan images of impact damage for the $4 \mathrm{~mm}$ thick plates impacted at 15J. The unpinned plate also had an additional and much larger delamination at the interface between the last ply and its adjacent layer due to the bending effect $[5,12]$.

Fig. 3 shows delamination area plotted as a function of impact energy for all specimens tested. The results also show that the delamination area increased almost linearly with the impact energy, and for a given impact energy the pinned specimen had a smaller damage area than that of unpinned counterpart. The effect of z-pinning is significant and is ranked by the order of the specimen thickness.

The average damage area for each specimen thickness at a given impact energy is given in Table 3. For the $2 \mathrm{~mm}$ thick specimens impacted at $3 \mathrm{~J}$ and $5 \mathrm{~J}$ incident energies, the pinning reduced the damage area by 19-38\% and the effectiveness of the pins increased with the impact energy. For the $4 \mathrm{~mm}$ specimens impacted at 15J and 20J incident energies, the pins were much more effective at restricting the damage area, reducing the damage area by 40$46 \%$. The effectiveness of the pins also increased with the impact energy but the increase was not as great as for the $2 \mathrm{~mm}$ specimens. For the $6 \mathrm{~mm}$ specimens impacted at 20-40 J, the pins were even more effective at restricting the damage area than they were for the 4 mm specimens reducing the damage area by 58-64\%. However, the effectiveness of the pins decreased slightly with increasing impact energy.

The pins became more effective as the sample's thickness increased. This is due to the change of the failure mode. For a thinner plate the bending failure mode dominates resulting in matrix cracking (fibre splitting) near the back face of the laminate, whereas for a thicker panel the impact force is mostly reacted by the interlaminar shear stresses resulting in delamination damage [5]. In this work, the thin (2 mm thick) specimens failed more in bending mode than in transverse shear, but vice versa for the thick $(6 \mathrm{~mm})$ specimens. The pins are more effective in arresting or retarding delamination cracks from propagating under interlaminar shear stresses than responding to the bending stress that causes in-plane matrix cracking; hence pinning is more effective in the thicker laminates. The thin samples failed by a combination of in-plane matrix cracking and interlaminar fracture; the pins are only effective for the latter failure mode, i.e. delamination. 
The effectiveness of the pins in the $6 \mathrm{~mm}$ specimens decreased slightly as the impact energy reached the highest level of 40J. This means that the pins became less effective when the failure mode switched from delamination growth to perforation damage.

\subsection{Critical impact force, $P_{c r}$}

It is inappropriate for structural designers to use impact energy as a design parameter against impact damage. This is because the threshold impact energy for damage initiation is dependent on impact location, component dimensions and boundary conditions. Several studies have shown that delamination damage is initiated when the impact force reaches a critical value [12-15].

Fig. 4 shows an example of the force history of an impact event. There are three meaningful force values related to the damage process as identified by various researchers. Reference [14] provides clear definition of these forces which is given below. The load increases until a sudden drop occurs (at point A of the curve). The load at point A is defined as the critical force for onset of delamination, $P_{c r}$. This delamination process is accompanied by a rapid reduction of the force to a rest value $P_{r}$ (point $\mathrm{B}$ ) due to reduction in the transverse stiffness of the laminate. A reloading phase of the specimen to a maximum point $P_{\max }$ (point C) may occur if enough residual potential energy is stored in the impactor. In fact $P_{\max }$ is also related to the target plate stiffness after the initial impact damage at $P_{c r}$.

In this study the measured average critical impact forces for three different thicknesses are given in Table 4 for both pinned and unpinned samples. There are two observations based on these results. Firstly, for each thickness the pinned samples had a slightly lower critical impact force. This is due to the fact that z-pinning results in a more compliant laminate (reduction in the equivalent elastic modulus $E$ [16-17]), and this will lead to a reduction in $P_{c r}$ as will be demonstrated in the calculation of $P_{c r}$ below. Secondly, the difference in $P_{c r}$ between the pinned and unpinned samples increases as the laminate becomes thicker. This is due to the different failure modes of the thick and thin. Failure of the thin laminates $(2 \mathrm{~mm})$ was dominated by bending induced in-plane strains and to a lesser extent by the transverse shear strains, whereas the thicker plates $(4$ and $6 \mathrm{~mm}$ ) failed mainly due to delamination resulting from the interlaminar shear stresses caused by the impact force [5]. Extensive experimental work has shown that the critical force does not depend on impact energy and it is also independent of specimen dimensions and boundary conditions [11-15]. The independency of sample size and boundary conditions was also studied numerically and experimentally in [18]. However we have found that for each thickness higher impact energy resulted in a slightly lowered $P_{c r}$.

The critical impact force must be achieved for delamination damage to initiate. The following equation was proposed for estimating the value of the critical impact force [19]:

$$
P_{c r}=\sqrt{\frac{8 \pi^{2} E t^{3}}{9\left(1-v^{2}\right)} \cdot G_{I I C}}
$$

where $E$ is the equivalent elastic modulus of the laminate in the $0^{\circ}$ and $90^{\circ}$ direction, $v$ the Poisson's ratio, $t$ the laminate thickness, and $G_{I I C}$ the material fracture toughness under 
mode II loading. Given that $E$, $v$, and $G_{I I C}$ are material constants, the critical impact force is proportional to the sample's thickness at the order of $t^{3 / 2}$, which has been verified by experimental results [12-15].

Since $P_{c r}$ depends only on the material properties and plate thickness, it is also possible to predict the critical force of z-pinned laminates under impact loading. The values of $G_{I I C}, E$ and $v$ of z-pinned laminate are needed for eq. (1). Because the mode II delamination toughness $G_{I I C}$ is mainly a property of the resin matrix system, in this study the toughness value for unpinned laminate has been used as the delamination toughness for pinned laminate for predicting the onset of delamination damage. This assumption is not unreasonable. Resistance to mode II crack growth is provided by the component of the pin force that is parallel to the crack planes. This force component is proportional to the sine value of the pin rotation angle, which initially is zero and then increases as the pins rotate during crack growth. Test reported in [9] has confirmed that z-pinning does not improve the resistance to the onset of impact damage. It is in the delamination growth regime that z-pins are most effective $[9,20]$; hence the impact damage size is much reduced compared to the unpinned laminates. In this study, $G_{I I C}=530 \mathrm{~J} / \mathrm{m}^{2}$ was used, which was obtained from the test of 3-point end notch flexural samples of the same material [21]. This toughness value corresponds to $5 \%$ offset from the curve non-linearity. Regarding the elastic constant $E$, it has been found that the in-plane elastic moduli of z-pinned laminates are reduced as the result of pinning $[16,17]$. For similar materials the equivalent modulus $(E)$ of pinned laminates was found to be approximately $7-10 \%$ lower than the unpinned value [17]. By applying the laminate theory the calculated modulus $(E)$ is $51.5 \mathrm{GPa}$ for the unpinned laminate with quasi-isotropic layup. For the $2 \%$ density pinned laminate $E=48 \mathrm{GPa}$ (assuming $7 \%$ reduction), and $v=0.28$ for both pinned and unpinned laminates. The critical impact forces for the pinned and unpinned plates were then calculated and indicated in Fig. 5. These predicted $P_{c r}$ values are close to the lower bound of the experimentally measured critical forces. Allowing scatters in testing, the experimental average value shows that $P_{c r}$ is independent of the impact energy for a given thickness. The decrease in critical force of the pinned laminate is due to the reduction in the equivalent elastic constant $(E)$ of the pinned laminates.

In some situations it may be decided that delamination is to be avoided at all cost; in which case Eq. (1) is all that is needed for calculating the threshold force $P_{c r}$ provided that the impact force history can be either computed or measured. However, many designers will still prefer to evaluate the threshold energy, because it is easier to estimate the potential energy of impact incidents occurring in manufacture and service. After examining a large amount of impact test data, Schoeppner and Abrate [15] reported that a clear energy threshold for damage initiation is not apparent. An analytical method to calculate the energy threshold $\left(W_{c r}\right)$ was proposed by Davies et al [22]:

$$
W_{c r}=\frac{k}{n+1}\left[\frac{P_{c r}}{k}\right]^{\frac{n+1}{n}}+\sum_{0}^{\delta\left(P_{c r}\right)} P d \delta
$$

where $P_{c r}$ is the critical impact force, and $\delta$ is the plate central deflection under applied force $P$. The nonlinear force-displacement relation can be found by either a static FE analysis of the impacted panel with correct boundary conditions or the Timoshenko plate theory for 
simple geometries. Constant $k$ is the contact stiffness and in the classical Hertz contact problem $n=1.5$.

Experiments in [22] have shown that this method is accurate enough for predicting the onset of impact damage for both large and small quasi-isotropic laminated plates if there is no fibre breakage caused by impact. In this study, experimental tests were conducted to determine the energy threshold for the $2 \mathrm{~mm}$ thick plates. At 2J impact energy, no delamination was observed experimentally. At 3J energy, average delamination damage area of $103 \mathrm{~mm}^{2}$ for the pinned samples and $127 \mathrm{~mm}^{2}$ for the unpinned were observed (Table 3). The average maximum deflection at the impact point was $2.73 \mathrm{~mm}$ and $2.86 \mathrm{~mm}$ for the pinned and unpinned samples, respectively. Predicted energy threshold by Eq. (2) for damage initiation in the same sized quasi-isotropic $2 \mathrm{~mm}$ thick plate was just $2 \mathrm{~J}$ for fully clamped edges and 3J for simply-supported edges [22]. The test samples in this study were all supported in the condition close to the clamped case but not fully constrained, therefore the threshold energy should be between 2 and $3 \mathrm{~J}$ and indeed the test results has confirmed this.

\subsection{Impact force history}

The force vs. time histories of the pinned and unpinned specimens were recorded. A smooth trace with sinusoidal feature indicates little or no damage in the specimen. Drops in the trace or truncated peak force indicate damage with the amount of damage being proportional to the height of the drop and the number of drops. Fig. 6a shows the behaviour of the thinner plates $(2 \mathrm{~mm})$ impacted at $5 \mathrm{~J}$, whereas the response the thicker plates $(6 \mathrm{~mm})$ impacted at 20J is shown in Fig. 6b. High frequency oscillations are present through the whole duration of the event.

For the $2 \mathrm{~mm}$ specimen impacts, there were very few drops in the trace and the height of the drops was relatively small. This indicates little delamination damage in the specimens, and the main damage was caused by matrix cracking due to bending. For the 5J impacts (Fig. $6 a)$, the height of the drops of the pinned samples was slightly smaller than that of the unpinned indicating that the pinned specimens were less damaged than the unpinned specimens.

For the $6 \mathrm{~mm}$ thick specimens (Fig. 6b), the impact event for the unpinned specimens lasted slightly longer than that of the pinned. This is due to the difference in specimen toughness after the delamination initiation at $P=P_{c r}$. The pinned specimens were tougher (hence less damage propagation) than the unpinned samples and therefore could recover faster from the impact event and hold a higher peak force after damage initiation. The pinned specimens had a smoother trace compared to the unpinned, indicating less damage to the pinned specimens. For all impact energies, the height of the force drops in pinned samples was much smaller than that of the unpinned. These drops were also less frequent for the pinned specimens.

There are two possible explanations to why z-pinning does not improve the resistance to delamination initiation. Firstly, the bond between the pins and the base laminate is relatively weak due to the resin pockets around the pins. Secondly, the pins are initially placed vertical 
to the mode II crack plane; therefore they are not effective in resisting damage initiation. After damage initiation, the resistance to mode II crack growth is provided by the component of the pin traction force that is parallel to the crack plane and increases as the pins rotate during crack growth. Consequently, the damage area of pinned laminate was much smaller even though the damage was initiated at a slightly lower critical force compared to the unpinned plate. Hence the reduction in delamination area is due to the pins traction action during crack growth rather than the physical bond.

\subsection{Energy absorption during impact}

The energy absorbed by the specimen is calculated by integrating the impact force over the plate centre deflection using the recorded force-deflection plots. Fig. 7 shows the absorbed energy versus the actual impact energy. In all cases, the pinned specimens absorbed less energy than the unpinned specimens. As the thickness of the specimen increased and as the impact energy increased, the difference in the absorbed energy between the pinned and unpinned also increased. Because all specimens were supported with the same boundary conditions, the decrease in absorbed energy means that less energy was consumed in damage growth in the pinned specimens. Some dissipated energy in the pinned samples is associated with the pins pulling out process, which also absorbs energy. However, since impact damage is dominated by mode II delamination, the amount of energy dissipation due to z-pin traction is relatively small compared to that of mode I fracture, which is discussed in the next section.

\subsection{CAI strength}

All the $4 \mathrm{~mm}$ thick specimens and selected $6 \mathrm{~mm}$ specimens (three pinned and three unpinned for each energy level) were compressed to failure. The $2 \mathrm{~mm}$ thick samples were not subjected to CAI testing. For both the $4 \mathrm{~mm}$ and $6 \mathrm{~mm}$ specimens, the ultimate strength of the undamaged plain laminate under uniaxial compression was predicted to be $515 \mathrm{MPa}$ using the Tsai-Hill failure criterion. Details of calculation can be found in [11]. Due to the limited numbers of test samples, no compression test was performed for undamaged plates. The CAI tests show that the residual strength for unpinned samples was about 150-170 MPa for the $4 \mathrm{~mm}$ plates and 140-225 MPa for the $6 \mathrm{~mm}$ thick plates. This result suggests that all the specimens failed by delamination propagation caused by local buckling that initiated at the impact damage location. Evidence of the local buckling can be found in Fig. 8. Due to the traction force offered by the z-fibres, the pinned specimens had much smaller damage size and significantly slower delamination growth rate; it took approximately five seconds from visible damage growth to final failure for the unpinned specimens while it took an approximately six times longer loading process for the pinned specimens. The pinned specimens did not fail until the visible damage had extended to the entire width of the pinned area. Consequently, the CAI strength of the pinned samples was significantly higher than that of the unpinned samples. The local buckling failure mode is sketched in Fig. 9 where the z-fibre traction force (bridging action) is also indicated. The effectiveness of zpinning is mainly due to the process of z-pin pullout which consumes large amounts of energy as a result of the friction between the z-pins and the surrounding base laminate. 
The average CAI strength values are presented in Table 5 and individual sample's residual strength as function of impact energy are presented in Fig. 10. All experimental results, including two anomalous ones, are included. The pinned specimens all failed at approximately $45 \%$ higher stress than the unpinned specimens. The only exception was the $6 \mathrm{~mm}$ thick specimens impacted at $20 \mathrm{~J}$. This may be due to the fact that the pinned $6 \mathrm{~mm}$ specimens impacted at $20 \mathrm{~J}$ were the first specimens subjected to compression testing. The first two specimens tested were not clamped into the support with the same force as all the other specimens. If these two anomalous results are removed, the difference between the pinned and unpinned results becomes $42 \%$. The degree of CAI strength improvement was found to be relatively independent of specimen thickness and impact energy.

The compressive failure strains of all unpinned samples were above $0.6 \%$, whereas they were above $0.9 \%$ for all pinned samples. If a factor of 1.5 were introduced to account for manufacturing differences and hot/wet performance of the laminate, a conservative design strain to failure limit would be $0.4 \%$ for the unpinned specimens and $0.6 \%$ for the pinned specimens - a $50 \%$ improvement.

\subsection{Z-pin bridging effect in mode I delamination}

The significant improvement in residual compressive strength by z-pinning can be explained by two factors. Firstly, the impact damage area is considerably smaller for the pinned plates resulting in higher CAI strength; the amount of improvement depends on sample's thickness and impact energy, but the reduction in impact damage area is relatively small due to z-pin bridging the mode II dominated fracture as discussed in Section 3.4. However, the difference in CAI strength between the pinned and unpinned is much larger than that in impact damage area and the improvement by pinning remained relatively constant at $42-45 \%$ for all specimen thicknesses and all impact energies, suggesting a second factor that is independent of the sample thickness and impact damage size. It is the z-fibre bridging mechanism for mode I fracture that significantly delays the delamination crack growth.

The CAI test in this study is dominated by the mode I interlaminar delamination fracture as illustrated in Fig. 9. The actual damage pattern in this study is complex with multiple layers of delamination (Fig. 8) and is very difficult to model in details. However, the effect of z-pin bridging mode I crack can be demonstrated quantitatively by a simple double cantilever beam (DCB) model. This is discussed below.

There are studies on the bridging effects offered by through-thickness reinforcements, such as stitching [23] and z-pinning [24-25]. Our recent work on z-pinned double cantilever beam [25] has found that the effectiveness of z-pinning is mainly owing to the formation of a large scale bridging (LSB) zone (see FE model in Fig. 11). Once a delamination crack has propagated several millimetres into the z-fibre field, those pins within the LSB zone will bridge the delamination crack. The LSB process can slow down or even temporally arrests the delamination crack. The mechanism of this bridging effect is the z-fibre pullout process during stable crack growth, which applies traction force to the crack surface. This process absorbs considerable amount of the stored strain energy that would otherwise be consumed for delamination growth. 
The assumption made by linear elastic fracture mechanics that all energy dissipations are included in the fracture energy and confined in a small zone of the damage front is not valid for z-pinned laminates. A recent study [25] has shown that the irreversible energy dissipation due to z-pin pulling out is the dominant term in the energy balance equation and thus it enhances the apparent fracture toughness of the reinforced laminates. This can be demonstrated as follows. With reference to the mode I delamination of z-pinned laminate, define:

$$
G_{I}=\frac{1}{B} \cdot\left(\frac{d W}{d a}-\frac{d U_{e}}{d a}\right), G_{I C}=\frac{1}{B} \frac{d \Gamma}{d a}, \quad \Phi_{i r}=\frac{1}{B} \cdot \frac{d U_{i r}}{d a}
$$

where, $G_{I}$ is the strain energy release rate due to applied force, $G_{I C}$ the fracture toughness of unpinned laminate (a material property), and $\Phi_{i r}$ the energy dissipation rate due to the process of z-pins pullout, which is the toughening mechanism of z-pinned laminates. $W$, $U_{e}, U_{i r}$ and $\Gamma$ are respectively the total external work, stored elastic strain energy, irreversible energy dissipation and energy for creating new fracture surfaces, and $B$ is the thickness of DCB sample. Therefore, the Griffith type fracture criterion for z-pinned laminates can be written as:

$$
G_{I}=G_{I C}+\Phi_{i r}
$$

These energy rates have been calculated for a pinned DCB specimen using the finite element method and the relation of the strain energy release rate with the apparent fracture toughness are found [25]. A sample calculation of various energy rates is presented in Fig. 12 as a demonstrator. The result indicates that $\Phi_{i r}$ is not a material constant; it depends also on the pinning parameters, crack length, and crack opening displacement. As the crack propagates $\Phi_{i r}$ increases rapidly and when the crack is sufficiently long (e.g. $a>20 \mathrm{~mm}$ in this case) $\Phi_{i r}$ is a magnitude higher than $G_{I C}$. It is the increased apparent fracture toughness $\left(G_{I C}+\Phi_{i r}\right)$ that provides increased CAI strength for z-pinned laminates. Therefore z-pinning is very effective for damage tolerance design especially under the mode I dominated loading.

It should be pointed out that the fracture toughness values (for both pinned and unpinned) obtained from the DCB configurations with unidirectional plies are much lower than the actual fracture toughness of the quasi-isotropic laminates in the CAI tests. The latter have higher fracture toughness due to the in-plane fibre bridging action on multiple layer delamination cracks. Nevertheless, DCB test still provides valuable material characteristics for structural design. Another point to make is that material improvement alone is not enough; integration of advanced materials with new design concept especially detailed design at critical locations should be the way forward for structural application of the zfibre technology. 


\section{CONCLUSIONS}

Z-fibre pinning improves the resistance to low velocity impact. For all specimen thicknesses and impact energies studied in this work, the pinned specimens suffered less damage than the unpinned specimens; pinning has reduced damage area by up to $64 \%$ depending on sample's thickness and impact energy. Pinning was more effective for the thicker specimens as well as for the higher impact energy.

For pinned laminate, the critical impact force is slightly lowered whereas the maximum impact force is higher than that of unpinned samples under the same impact energy. The reduced critical force is due to the pinned laminates being more compliant, whereas the increased maximum force is the consequence of less impact damage in the pinned plates. The effectiveness of z-pinning is in the delamination propagation stage rather than the damage initiation stage.

Z-pinning also significantly improves the compression-after-impact strength. The pinned specimens had an approximately 45\% higher residual strength than the unpinned counterparts. The degree of CAI strength improvement is found to be relatively independent of specimen thickness and impact energy, and it is dependent on the magnitude of z-fibre traction force that is a function of pinning parameters and crack length. All the pinned specimens had higher failure strains than the unpinned specimens. Results in this work indicate that the use of z-fibres could increase the design strain limit for aircraft structures by about $50 \%$.

\section{ACKNOWLEDGEMENTS}

MG was supported by the UK DTI CARAD programme; LH was supported by the Canadian Forces while she conducted the research at Cranfield University. The authors are also grateful to Dr. D. Cartié for helpful discussions and Aztex Inc. for providing Z-fibres.

\section{REFERENCES}

1. Dorey G. Impact damage in composites - Development, consequences and prevention, Proc. of ICCM 6 \& ECCM 2, Vol. 3, London, 1987, pp. 3.1-3.26.

2. Davies GAO. Aircraft Structures. The Aeronautical Journal 1996; 100: 523-529.

3. Davies GAO, Zhang X. Predicting impact damage of composite stiffened panels. The Aeronautical Journal 2000; 104: 97-103.

4. Davies GAO, Olsson R. Impact on composite structures. The Aeronautical Journal 2004; 108: 541-563.

5. Zhang, X. Impact damage in composite aircraft structures - experimental testing and numerical simulation. Proc Instn Mech Engrs, Part G, J Aerospace Engineering 1998; 212: 245-259.

6. Dickinson LC, Farley GL, Hinders MK. Translaminar reinforced composites: a review. Journal of Composites Technology \& Research 1999; 21: 3-15.

7. Freitas G, Magee C, Dardzinski P, Fusco T. Fibre insertion process for improved damage tolerance in aircraft laminates. J Adv Mater 1994; 24: 36-43.

8. Freitas G, Fusco T, Campbell T, Harris J, Rosenberg S. Z-Fiber ${ }^{\mathrm{TM}}$ technology and products for enhancing composite design. Proceedings of $83^{\text {rd }}$ Meeting of AGARD Structures \& Materials Panel. 1996. 
9. Partridge IK, Cartié DDR, Bonnington T. Manufacture and performance of Z-pinned composites. Chapter 3 in Advanced Polymeric Materials: Structure Property Relationships, eds S Advani and G Shonaike, CRC Press LLC, April 2003.

10. Clarke A, Greenhalgh E, Meeks C, Jones C. Enhanced structural damage tolerance of CFRP primary structures by z-pin reinforcement. Proc $44^{\text {th }}$ AIAA/ASME/ASCE/AHS Structures, Structural Dynamics and Materials Conference, Norfolk, April 2003. AIAA-2003-1679.

11. Hounslow LE. The influence of z-pinning on low velocity impact performance of laminated carbon composites, MSc Thesis, Cranfield University, 2000.

12. Davies GAO, Zhang X. Impact damage prediction in carbon composite structures, Int J Impact Engng 1995; 16: 149-170.

13. Sjoblom P, Hwang B. Compression-after-impact: the $\$ 5,000$ data point. Proc $34^{\text {th }}$ Int SAMPE Symposium, Reno, Nevada, May 8-11, 1989, pp. 1411-1421.

14. Cartie DDR, Irving PE. Effect of resin and fibre properties on impact and compression after impact performance of CFRP. Composites A: Applied Science \& Manufacturing 2002; 33: 483-493.

15. Schoeppner GA, Abrate S. Delamination threshold loads for low velocity impact on composite laminates. Composites Part A 2000; 31: 903-915.

16. Dickinson LC, Farley GL, Hinders MK. Prediction of effective three-dimensional elastic constants of translaminar reinforced composites. J Compos Mater 1999; 33:1002-29.

17. Grassi M, Zhang X, Meo M. Numerical prediction of stiffness and stresses in z-fibre reinforced laminates. Composites Part A 2002; 33:1653-64.

18. Olsson R. Analytical prediction of large mass impact damage in composite laminates. Composites Part A 2001; 32: 1207-1215.

19. Davies GAO, Robinson P. Predicting failure by debonding/delamination. In: debonding/delamination of composites. AGARD-CP-530, Neuilly sur Seine: AGARD, 1992. p. 5.1-5.28.

20. Rugg KL, Cox BN, Massabo R. Mixed mode delamination of polymer laminates reinforced through the thickness by z-fibres. Composites Part A 2002; 33:177-190.

21. Bitsianis NG. The influence of z-pinning on toughness and impact performance of carbon fibre polymer composite materials. MSc Thesis, Cranfield University, 1999.

22. Davies GAO, Hitchings D, Wang J. Prediction of threshold impact energy for onset of delamination in quasi-isotropic carbon/epoxy composite laminates under low-velocity impact. Comp Sci Tech 2000; 60: 1-7.

23. Dransfield AK, Jain LK, Mai YW. On the effect of the stitching in CFRP- I. Mode I delamination toughness. Comp Sci Tech 1998; 58: 815-827.

24. Yan, W, Liu H-Y \& Mai Y-W. Numerical study on the mode I delamination toughness of z-pinned laminates, Comp Sci Tech 2003; 63: 1481-1493.

25. Grassi M, Zhang X. Finite element analyses of Mode-I interlaminar delamination in zfibre reinforced composite laminates. Comp Sci Tech 2003; 63: 1815-1832. 
Table 1. Basic material properties for T300/914C at $20^{\circ} \mathrm{C}$ (units for moduli: $\mathrm{GPa}$ ).

\begin{tabular}{cccc}
\hline$E_{11}$ & $E_{22}$ & $G_{12}$ & $v_{12}$ \\
\hline 135 & 8.3 & 4.5 & 0.28 \\
\hline
\end{tabular}

Table 2. Impact test parameters.

\begin{tabular}{ccccccc}
\hline $\begin{array}{c}\text { Specimen } \\
\text { Thickness } \\
(\mathrm{mm})\end{array}$ & $\begin{array}{c}\text { Impact } \\
\text { Energy } \\
(\mathrm{J})\end{array}$ & $\begin{array}{c}\text { Drop } \\
\text { Mass } \\
(\mathrm{Kg})\end{array}$ & $\begin{array}{c}\text { Drop } \\
\text { Height } \\
(\mathrm{m})\end{array}$ & $\begin{array}{c}\text { Impact } \\
\text { Velocity } \\
(\mathrm{m} / \mathrm{s})\end{array}$ & $\begin{array}{c}\text { No. of } \\
\text { samples } \\
(\text { unpinned })\end{array}$ & $\begin{array}{c}\text { No. of } \\
\text { samples } \\
(\text { pinned })\end{array}$ \\
\hline 2 & 3 & 2.2 & 0.132 & 1.65 & 3 & 3 \\
& 5 & & 0.230 & 2.13 & 3 & 3 \\
\hline 4 & 15 & 4.7 & 0.324 & 2.52 & 3 & 3 \\
& 20 & & 0.432 & 2.91 & 3 & 3 \\
\hline 6 & 20 & 11.3 & 0.179 & 1.88 & 4 & 4 \\
& 30 & & 0.268 & 2.30 & 4 & 4 \\
& 40 & & 0.360 & 2.66 & 4 & 4 \\
\hline
\end{tabular}

Table 3. Impact test result - average damage area

\begin{tabular}{ccccc}
\hline $\begin{array}{c}\text { Specimen } \\
\text { thickness } \\
(\mathrm{mm})\end{array}$ & $\begin{array}{c}\text { Impact } \\
\text { energy } \\
(\mathrm{J})\end{array}$ & $\begin{array}{c}\text { Average damage } \\
\text { area }\left(\mathrm{mm}^{2}\right) \\
(\text { unpinned })\end{array}$ & $\begin{array}{c}\text { Average damage } \\
\text { area }\left(\mathrm{mm}^{2}\right) \\
(\text { pinned })\end{array}$ & $\begin{array}{c}\text { Difference } \\
(\%)\end{array}$ \\
\hline 2 & 3 & $127( \pm 5)$ & $103( \pm 12)$ & 18.9 \\
\hline 4 & 5 & $307( \pm 16)$ & $191( \pm 21)$ & 37.8 \\
\hline 6 & 15 & $917( \pm 64)$ & $552( \pm 31)$ & 39.8 \\
& 20 & $1382( \pm 92)$ & $748( \pm 66)$ & 45.9 \\
\hline & 20 & $1728( \pm 152)$ & $629( \pm 19)$ & 63.6 \\
& 30 & $2269( \pm 95)$ & $848( \pm 28)$ & 62.6 \\
\hline
\end{tabular}

The numbers in parentheses indicate standard deviation. 
Table 4. Impact test result - critical impact force (unit: N)

\begin{tabular}{ccccc}
\hline $\begin{array}{c}\text { Specimen } \\
\text { thickness } \\
(\mathrm{mm})\end{array}$ & $\begin{array}{c}\text { Impact } \\
\text { energy } \\
(\mathrm{J})\end{array}$ & $\begin{array}{c}P_{\text {crit }} \\
\text { (unpinned) }\end{array}$ & $\begin{array}{c}P_{\text {crit }} \\
\text { (pinned) }\end{array}$ & $\begin{array}{c}\text { Difference } \\
(\%)\end{array}$ \\
\hline 2 & 3 & $1616( \pm 72)$ & $1579( \pm 115)$ & 2.3 \\
& 5 & $1591( \pm 49)$ & $1569( \pm 18)$ & 1.4 \\
\hline 4 & 15 & $5355( \pm 215)$ & $4627( \pm 47)$ & 13.6 \\
& 20 & $4978( \pm 67)$ & $4510( \pm 153)$ & 9.4 \\
\hline 6 & 20 & $9556( \pm 390)$ & $8564( \pm 423)$ & 10.4 \\
& 30 & $9370( \pm 302)$ & $8319( \pm 583)$ & 11.2 \\
& 40 & $9012( \pm 235)$ & $7740( \pm 209)$ & 14.1 \\
\hline
\end{tabular}

The numbers in parentheses indicate standard deviation.

Table 5. Residual compressive strength ${ }^{\mathrm{a}}$

\begin{tabular}{ccccc}
\hline $\begin{array}{c}\text { Specimen } \\
\text { thickness } \\
(\mathrm{mm})\end{array}$ & $\begin{array}{c}\text { Impact } \\
\text { energy } \\
(\mathrm{J})\end{array}$ & $\begin{array}{c}\text { Unpinned average } \\
\text { failure stress } \\
(\mathrm{MPa})\end{array}$ & $\begin{array}{c}\text { Pinned average } \\
\text { failure stress } \\
(\mathrm{MPa})\end{array}$ & $\begin{array}{c}\text { Difference } \\
(\%)\end{array}$ \\
\hline 4 & 15 & $171( \pm 16)$ & $310( \pm 23)$ & 44.8 \\
& 20 & $153( \pm 4)$ & $285( \pm 6)$ & 46.3 \\
\hline 6 & 20 & $223( \pm 1)$ & $342( \pm 38)$ & $34.8^{\mathrm{b}}$ \\
& 30 & $159( \pm 17)$ & $289( \pm 18)$ & 45.0 \\
& 40 & $140( \pm 3)$ & $252( \pm 17)$ & 44.4 \\
\hline
\end{tabular}

${ }^{a}$ Average strength values. The numbers in parentheses indicate standard deviation.

${ }^{\mathrm{b}}$ Reason for this anomalous experimental result is given in section 3.5 paragraph 2 . 


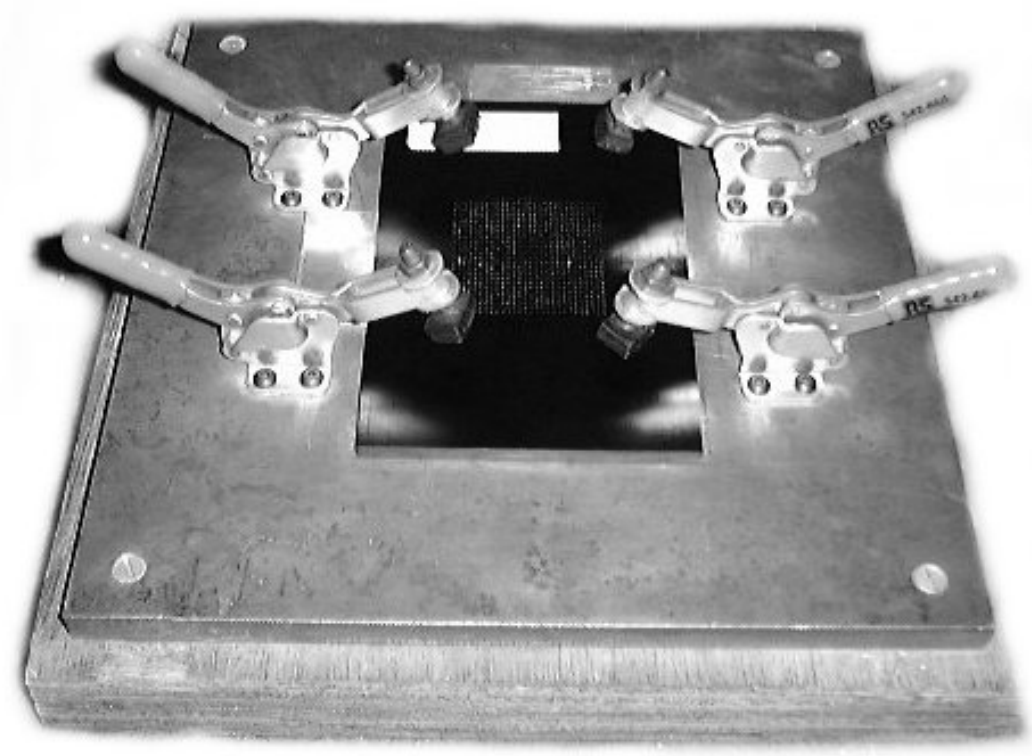

Fig. 1a. Specimen and impact support (note the pinned area in sample centre).

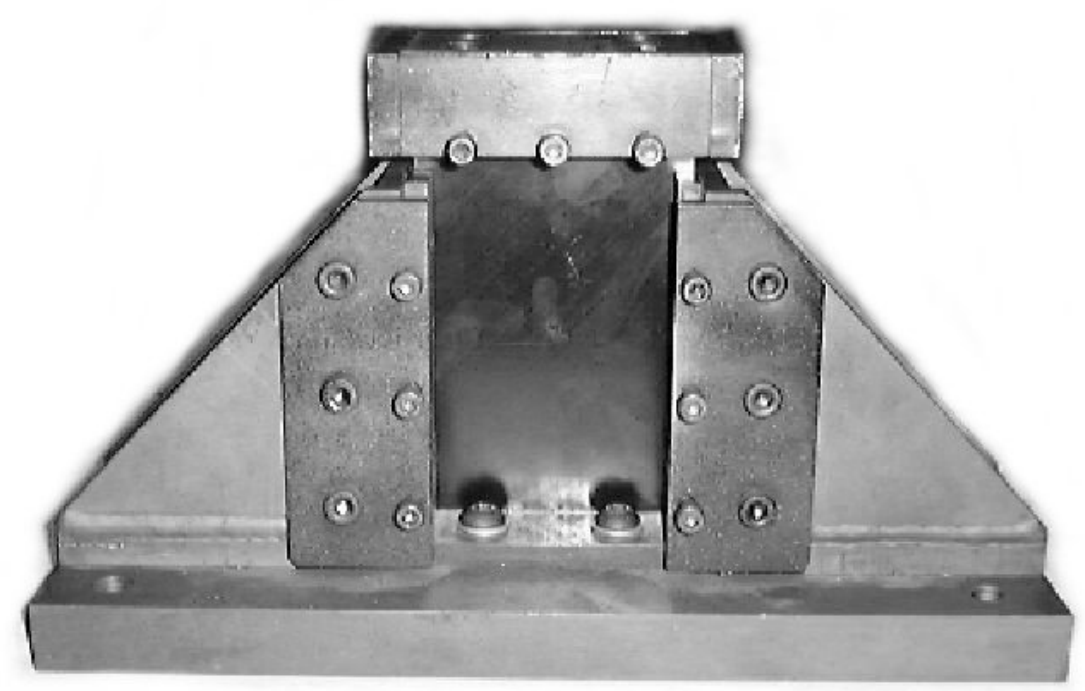

Fig. 1b. Compression-After-Impact (CAI) support rig. 

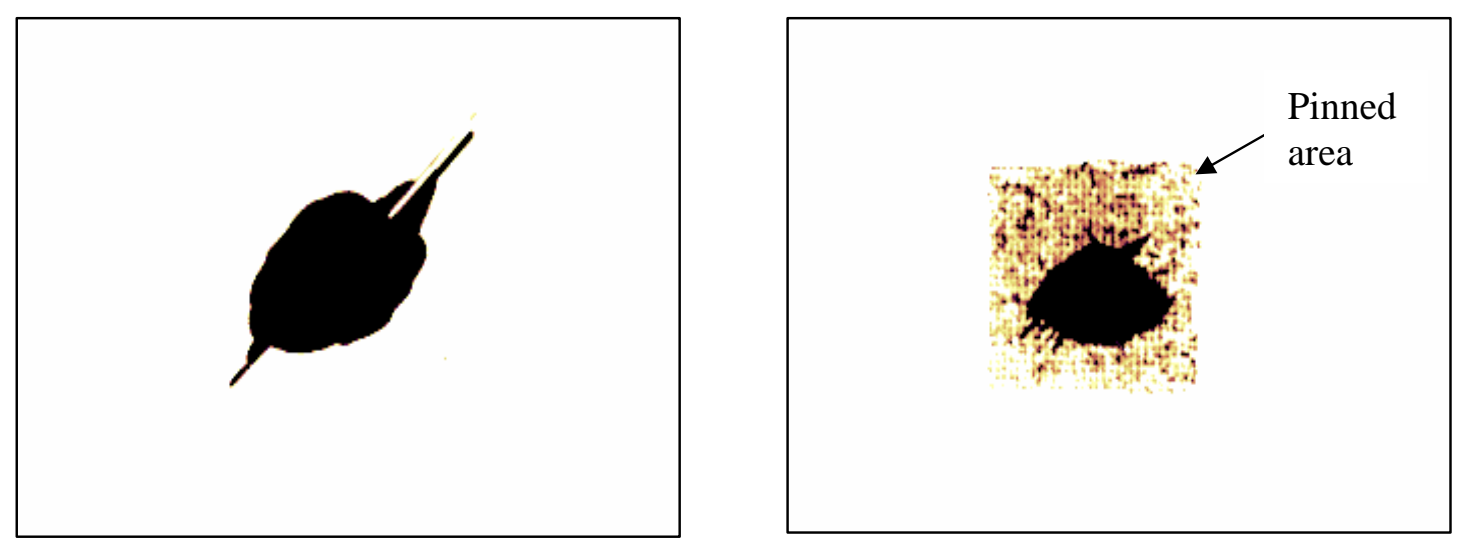

Fig. 2 C-scan images for (a) unpinned and (b) pinned 4 mm thick plates; both were impacted by $15 \mathrm{~J}$ energy.

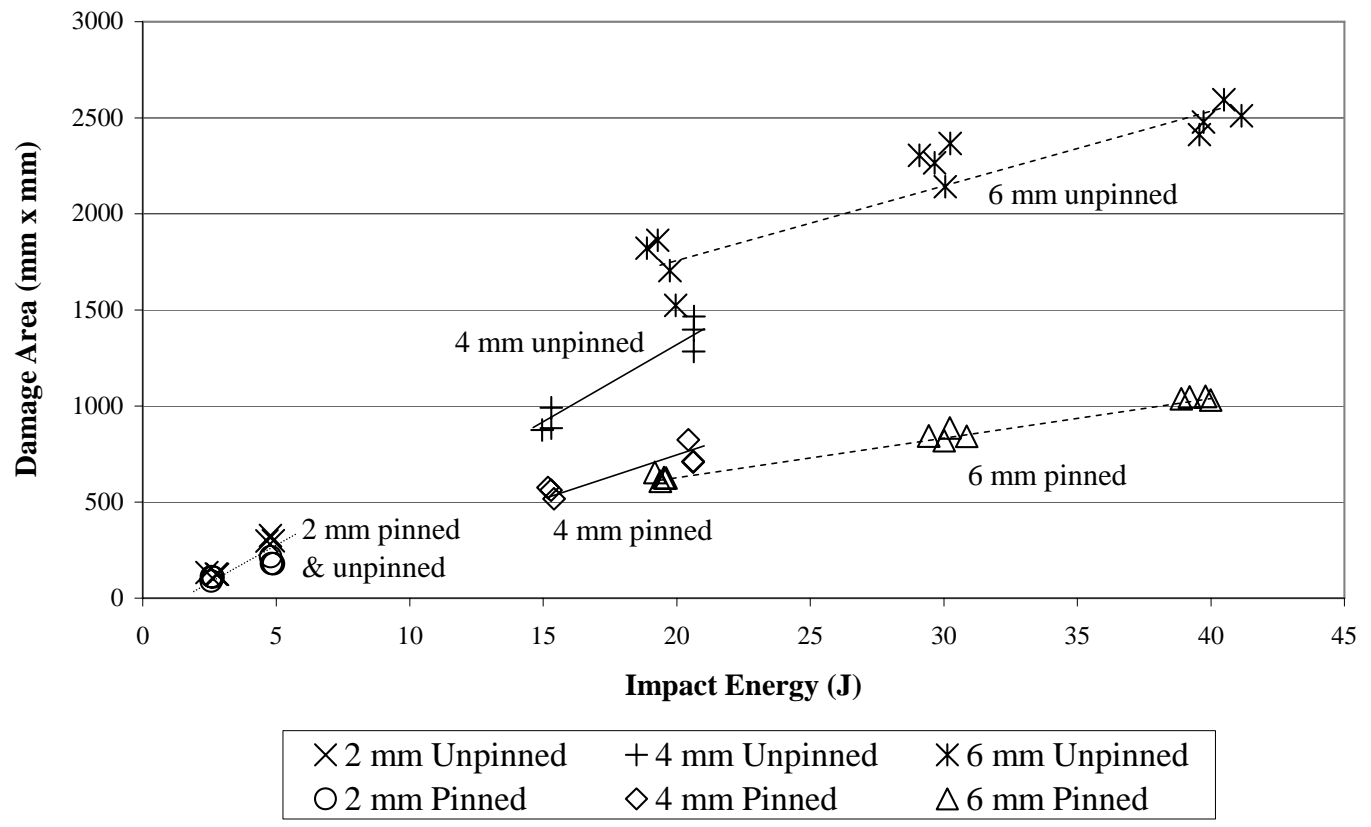

Fig. 3 Damage area versus impact energy (Note: lines are fitted through experimental data points to give clearer indication). 


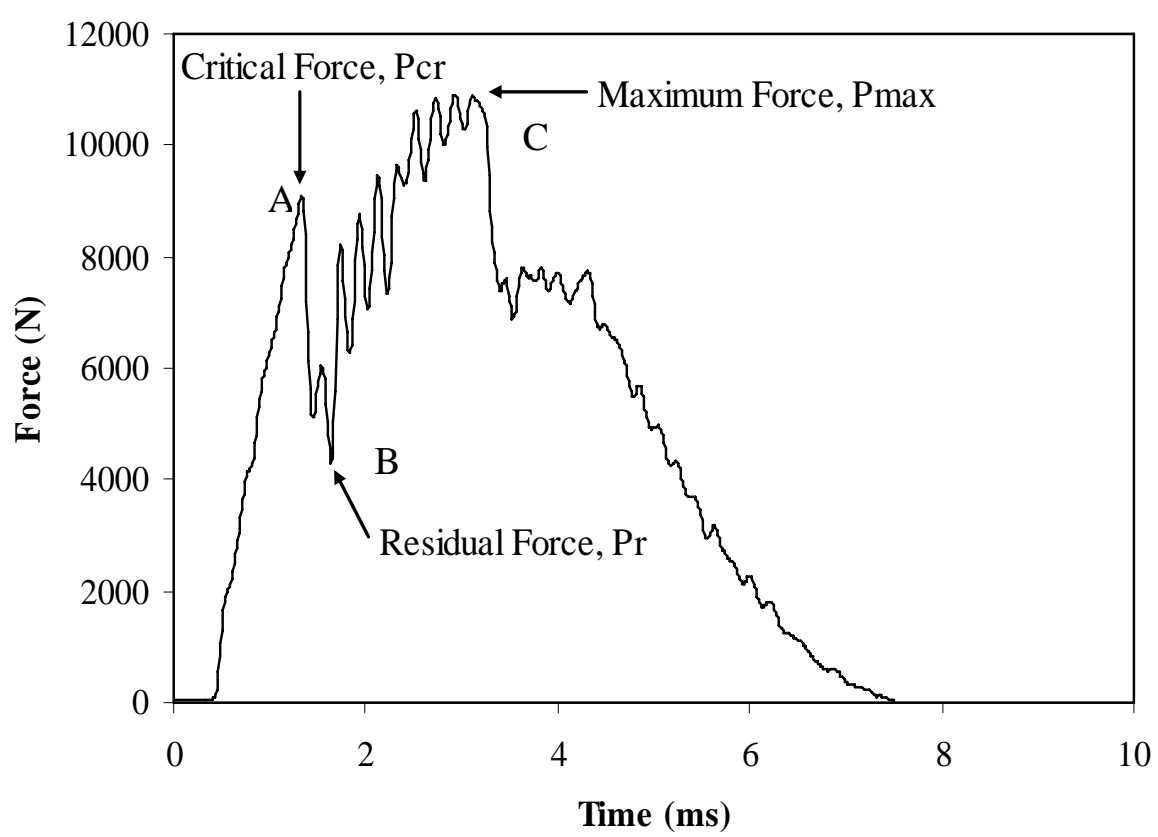

Fig. 4 Definition of impact forces: critical, residual, and maximum force.

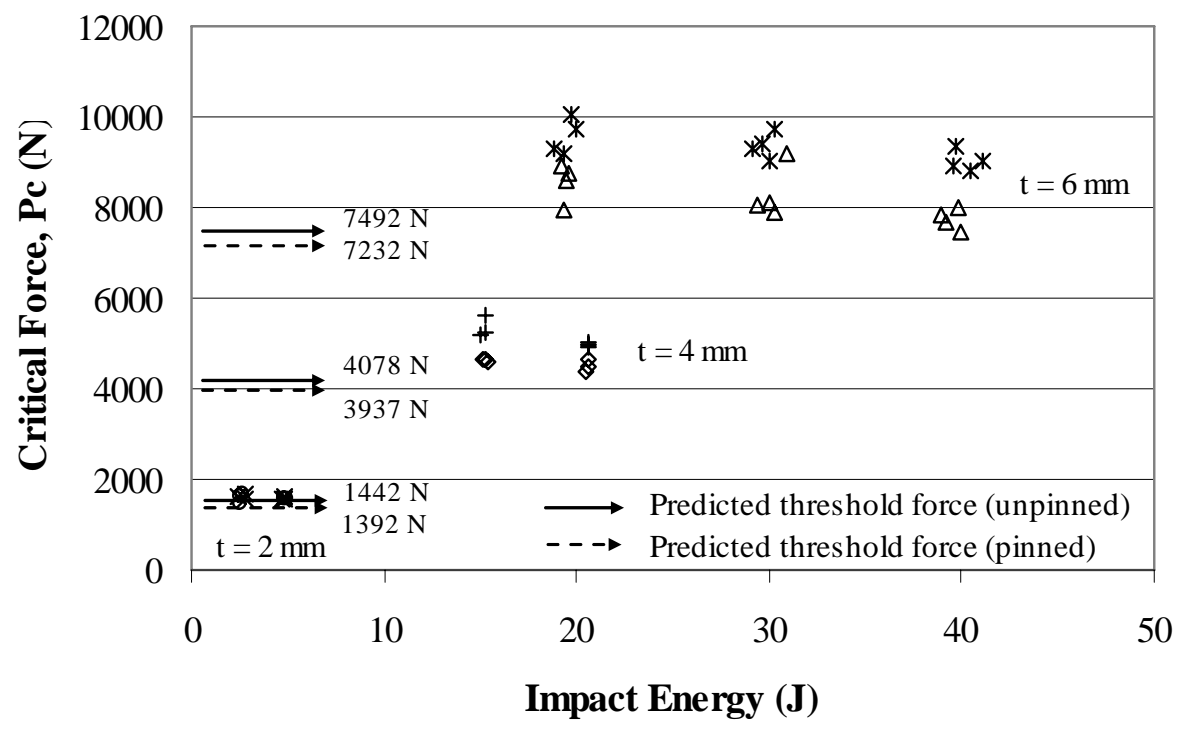

$\times 2 \mathrm{~mm}$ Unpinned $+4 \mathrm{~mm}$ Unpinned $* 6 \mathrm{~mm}$ Unpinned $\circ 2 \mathrm{~mm}$ Pinned $\diamond 4 \mathrm{~mm}$ Pinned $\quad \Delta 6 \mathrm{~mm}$ Pinned

Fig. 5 Predicted and measured critical impact forces in a variety of plate thickness. 


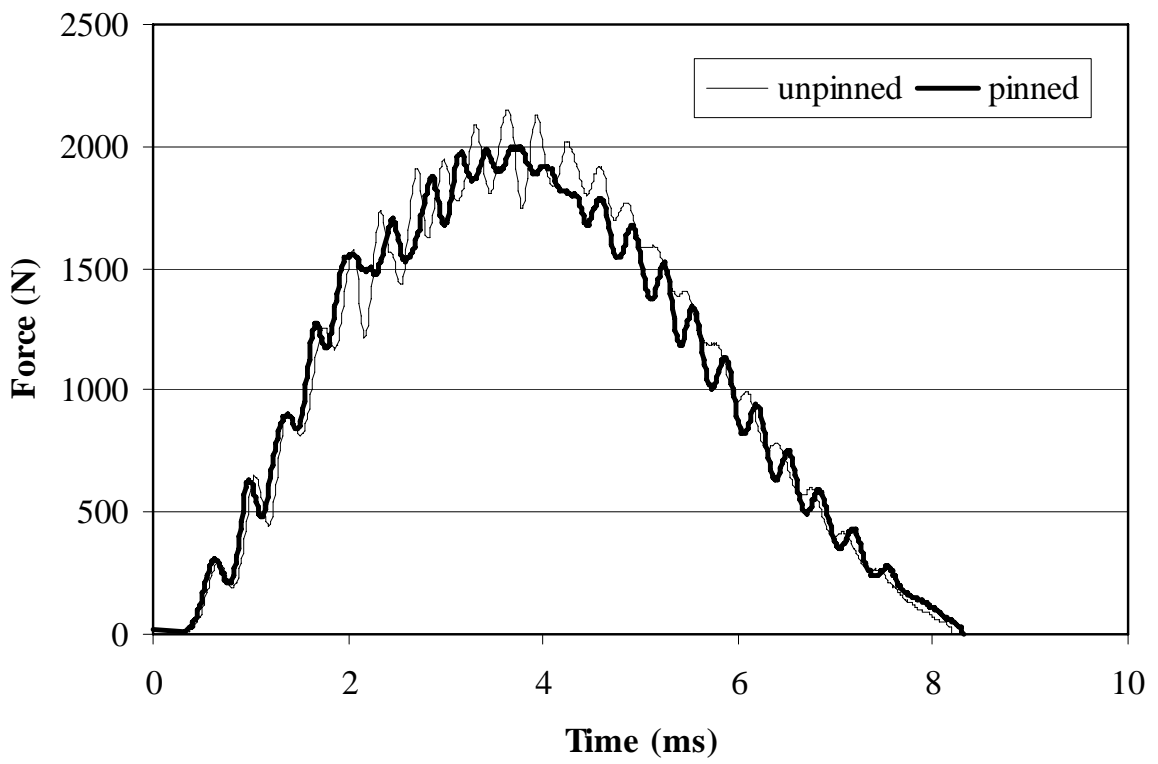

Fig. 6a Force versus time history for the thin (2mm thick) plates under $5 \mathrm{~J}$ impact energy.

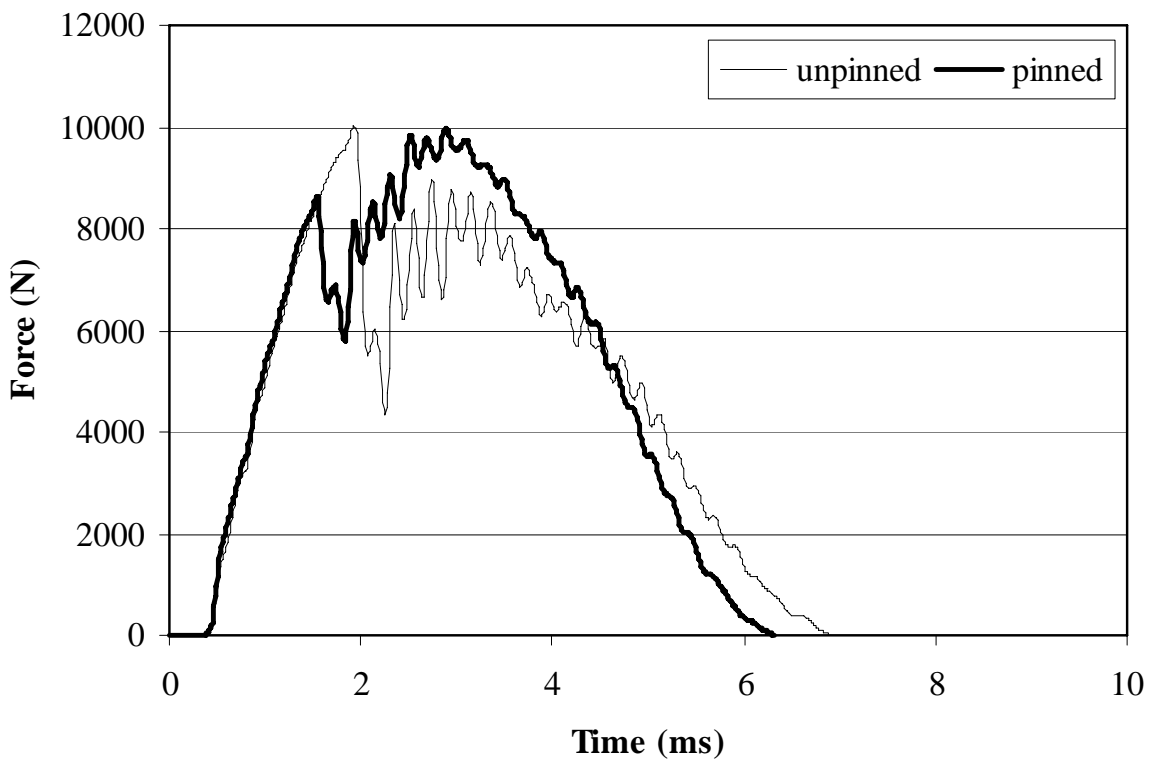

Fig. 6b Force versus time history for the thick (6 mm) plates under $20 \mathrm{~J}$ impact energy. 


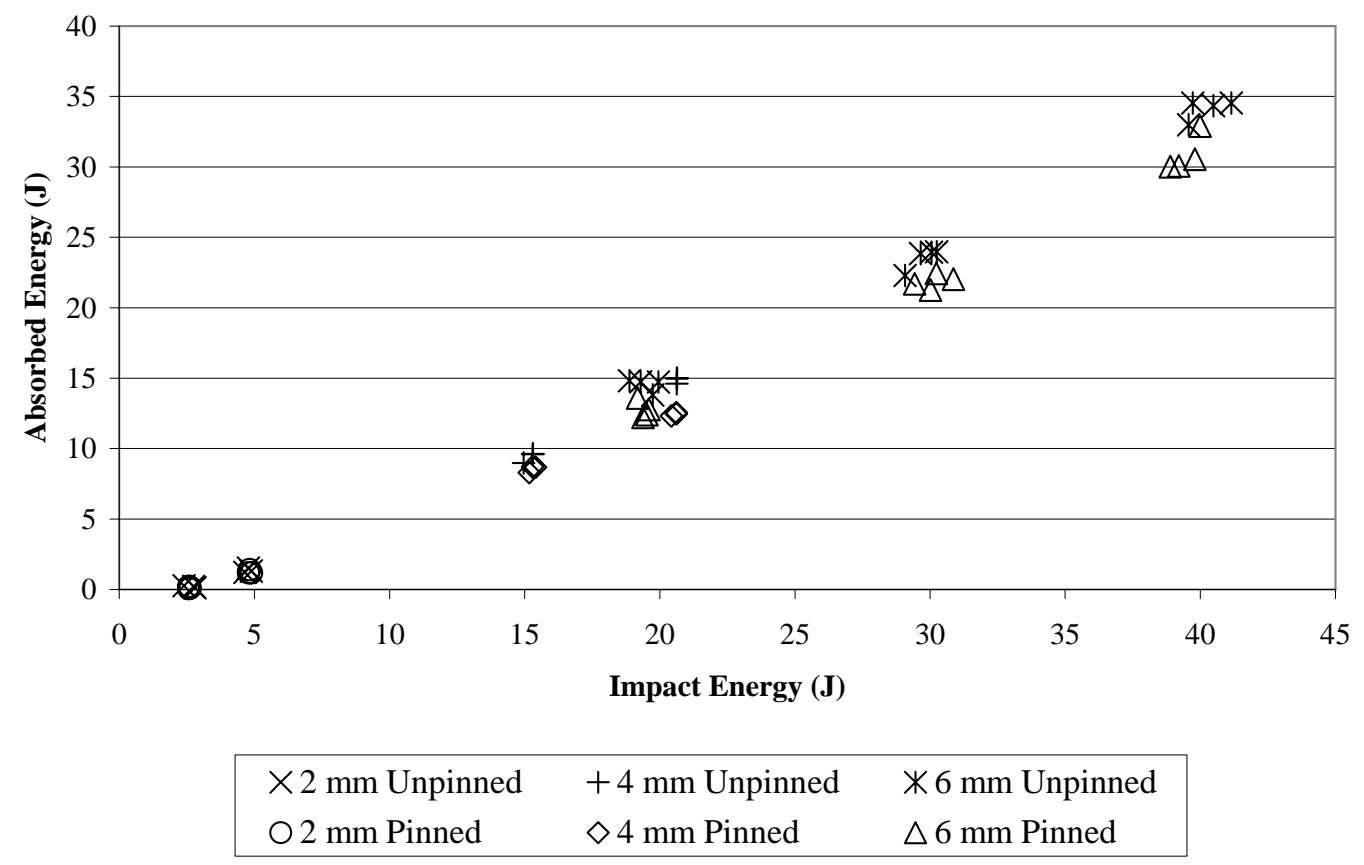

Fig. 7 Absorbed energy versus impact energy.

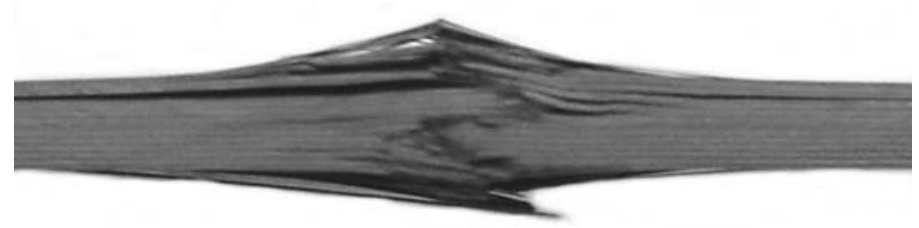

Fig. 8a Side view of local buckling failure during CAI test - unpinned $6 \mathrm{~mm}$ thick plate.

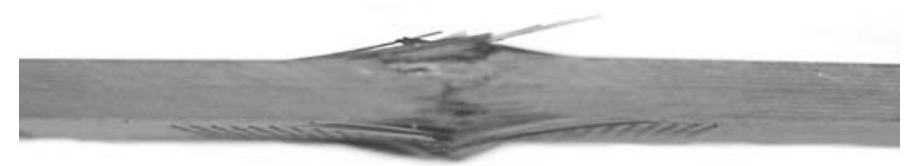

Fig. 8b Side view of local buckling failure during CAI test - pinned $6 \mathrm{~mm}$ thick plate. 


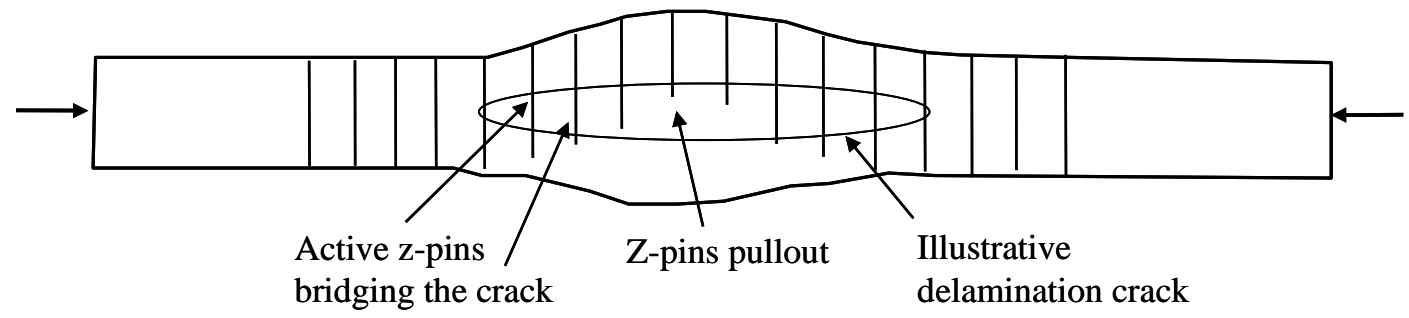

Fig. 9 Schematic of CAI test (side view) showing local buckling and z-pin bridging effect.

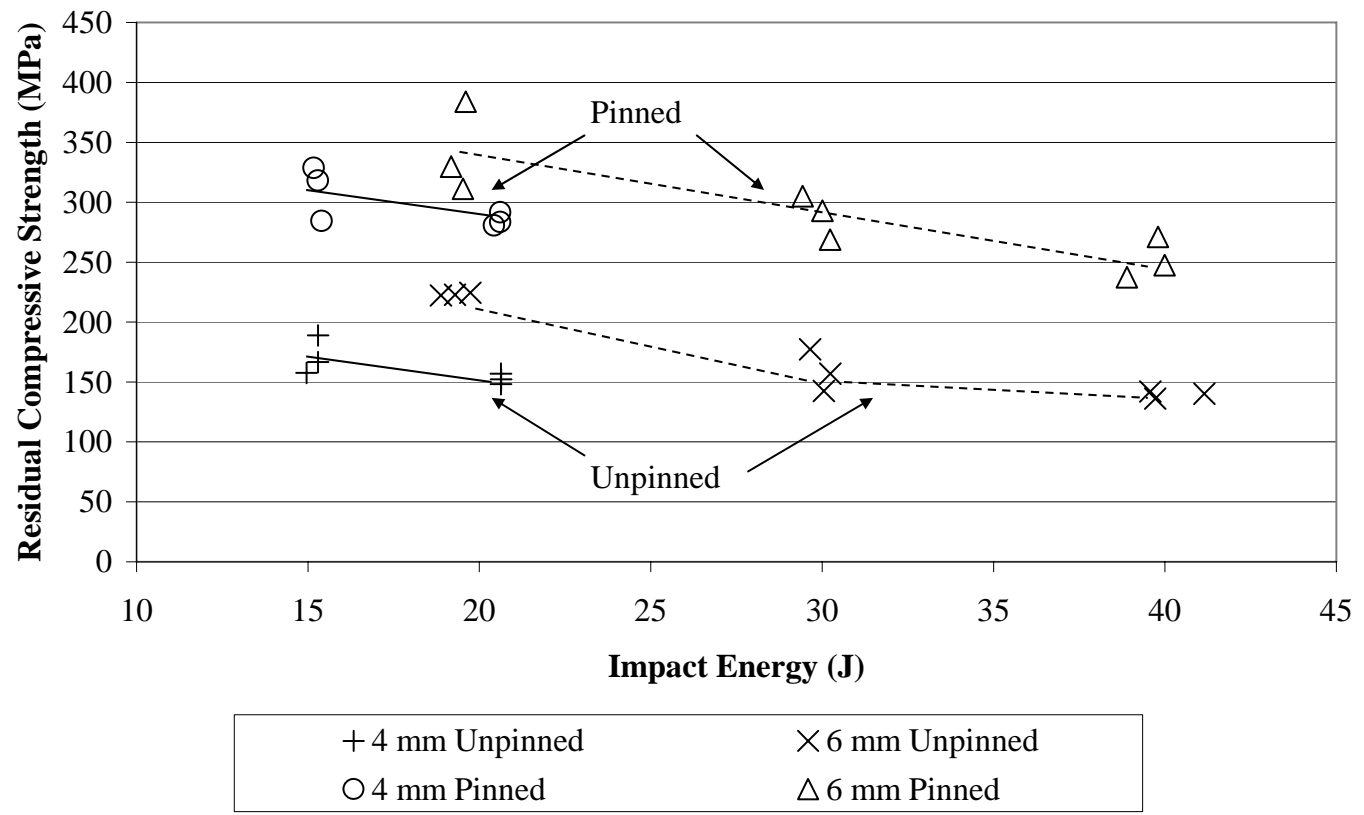

Fig. 10 Residual compressive strength vs. impact energy. (Note: lines are fitted through the experimental data points to give clearer indication). 


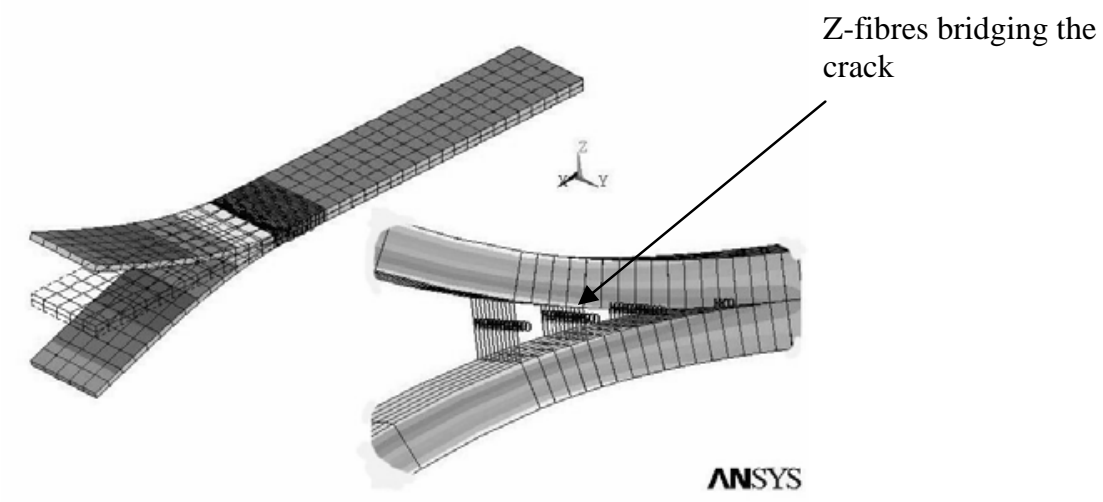

Fig. 11 FE model of a double-cantilever-beam (DCB) specimen.

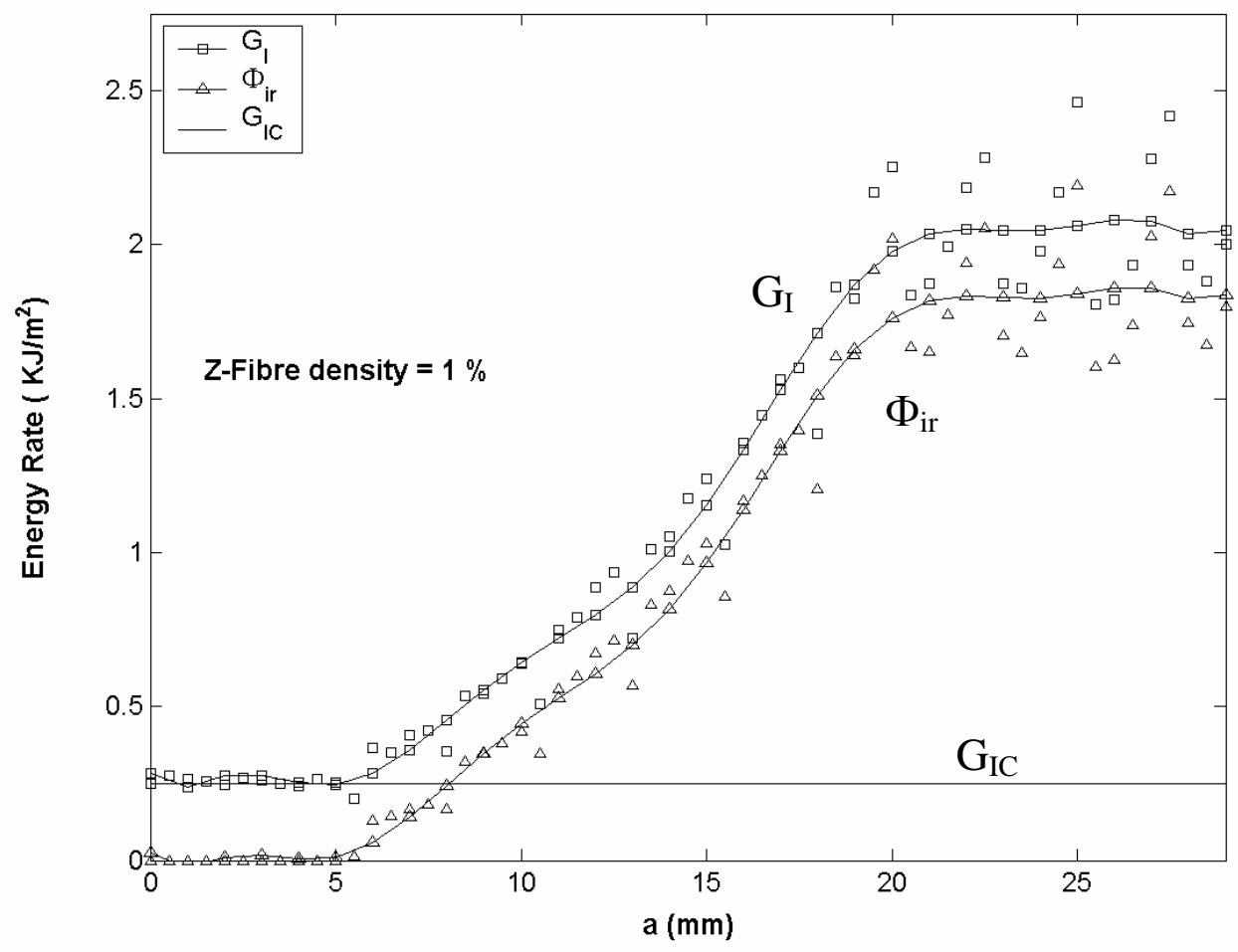

Fig. 12 Energy rates vs. delamination crack length (z-pin diameter $=0.28 \mathrm{~mm})$. 